\title{
Sensitivity of near-surface Tropical Instability Waves to submonthly wind forcing in the tropical Atlantic
}

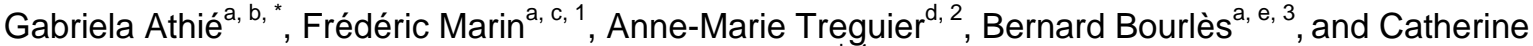 \\ Guiavarc'h ${ }^{\mathrm{d}, 4}$
}

\author{
a Université de Toulouse, UPS (OMP-PCA), LEGOS, 14 Avenue Edouard Belin, F-31400 Toulouse, France \\ ${ }^{b}$ IRD, LEGOS, F-29280 Plouzané, France \\ ${ }^{c}$ IRD, LEGOS, F-31400 Toulouse, France \\ d Laboratoire de Physique des Océans, CNRS-IFREMER-IRD-UBO, Ifremer, BP70, 29280 Plouzané, France \\ e IRD, LEGOS, Cotonou, Benin \\ 1 Tel.: +33 561333056 . \\ 2 Tel.: +33298224296. \\ 3 Tel.: +22921300354 . \\ ${ }^{4}$ Present address: NCOF, UK Met Office, Fitzroy Road, Exeter EX1 3PB, United Kingdom. Tel.: +44 \\ 1392885059.
}

*: Corresponding author : Gabriela Athié, Tel.: +52 6461750500, email address : gathie@cicese.mx

\begin{abstract}
:
This study demonstrates the sensitivity of the near-surface properties in the tropical Atlantic Ocean to the high-frequency of the winds in numerical simulations. At intra-seasonal timescales (2-50 days), two distinct period ranges dominate the variability in the upper ocean: periods between 2 and 20 days, which are essentially wind-forced and periods between 20 and 50 days, due mostly to Tropical Instability Waves (TIWs). Using a numerical model forced by different wind fields, it is shown that the characteristics of the intra-seasonal variability in the ocean surface mixed-layer are strongly dependent on the wind forcing. Submonthly winds are shown to force large variability in the upper ocean that can strikingly decrease the amplitude of the TIWs in the mixed-layer and their imprint on the horizontal distribution of sea surface temperatures. Wind products containing too much energy at submonthly periods thus prevent wind-forced simulations from reproducing a realistic surface signature of TIWS, when compared to satellite observations of sea surface temperature. In addition, submonthly wind variability may be responsible for part of the observed interannual variability of the TIW signature in the temperature. The impact of submonthly winds is strongest in the mixed-layer: beneath the mixed-layer, all simulations show similar characteristics of the TIWs.
\end{abstract}

Keywords: Equatorial Atlantic; Intra-seasonal variability; Tropical instabilities; Ocean mixed-layer; Sensitivity numerical experiments 


\section{Introduction}

Tropical ocean circulation is governed primarily by the seasonal evolution of the winds that control the variability from seasonal to interannual timescales. In the Atlantic Ocean, the seasonal cycle of Sea Surface Temperature (SST) is dominated by the appearance of a cold tongue in boreal summer, creating an intense meridional front in SST on both sides of the equator in the central and eastern parts of the basin. Superimposed on this cycle, prominent intra-seasonal fluctuations are observed from satellite images and historical time series observations. The intra-seasonal variability, defined here as the variability for periods between 2 and 50-days in the upper ocean $(0-150 \mathrm{~m})$, has two distinct origins: Tropical Instability Waves (TIWs), that are observed as spectacular undulations of the SST fronts in boreal summer in the western half of the basin; and wind-forced signals, mainly within the 220-day frequency band, which take place throughout the year.

Satellite images as well as in situ observations in temperature, zonal and meridional currents have documented the principal characteristics of TIWs in the Atlantic (e.g. Düing et al., 1975; Qiao and Weisberg, 1995; Wainer et al., 2003; Caltabiano et al., 2005; Bunge et al., 2006, 2007; Athié and Marin, 2008). They have periods between 20 and 50 days, wavelengths of $700-1200 \mathrm{~km}$ and westward phase velocities of 30-60 cm/s. TIWs are generated by the intense latitudinal shears between the components of the equatorial current system that become unstable at the surface and subsurface (e.g. Philander, 1978; Weisberg and Weingartner, 1988; Jochum et al., 2004). In the Atlantic as well as in the Pacific, TIWs play an important role in the mixed-layer heat balance. Temperature observations at the surface and subsurface (e.g. Hansen and Paul, 1984; Weisberg and Weingartner, 1988; Weisberg, 1988; Baturin and Niiler, 1997; Jochum et al., 2007) as well as modelling studies (e.g. Jochum et al., 2005; Peter et al., 2007) reveal that the net effect of TIWs is to warm the mixed layer in the equatorial band. Furthermore, TIWs play a crucial role in the heat exchanges between the surface and the deep ocean (Jochum et al., 2004).

Within the 2-20-day timescales, winds force additional intra-seasonal variability in the upper layers of the Atlantic Ocean. For instance, Garzoli (1987) reports significant coherence between the ocean and wind variability with two predominant peaks centered at 5 and 7 days. Those signals have been observed principally from time series of velocity and temperature at a few mooring sites along the equator (Garzoli, 1987; Wainer et al., 2003; Bunge et al., 2006), 
but also away from the equator along $3^{\circ} \mathrm{N}$ and $9^{\circ} \mathrm{N}$ (Garzoli, 1987). Unfortunately, the temporal resolution of satellite observations is insufficient to study the spatial distribution of the surface variability in detail at those frequencies in the ocean, both for SST and sea level anomalies.

While 15-day oscillations in the equatorial Atlantic have long been observed using temperature and velocity data in the ocean (Houghton and Colin, 1987; Garzoli, 1987) and in the atmosphere (Houghton and Colin, 1987; Grodsky and Carton, 2001; Janicot and Sultan, 2001; Mounier et al., 2006), it is only recently that they are thought to be an important part of the ocean intra-seasonal variability (Bunge et al., 2006, 2007; Guiavarc'h et al., 2008; Athié and Marin, 2008). This biweekly variability dominates the eastern side of the equatorial Atlantic (Han et al., 2008; Athié and Marin, 2008). It corresponds to equatorial mixed Rossby-gravity waves, also known as Yanai waves (Yanai and Mukarami, 1970), that are forced by meridional and/or zonal winds in the eastern Tropical Atlantic (Bunge et al., 2006, 2007; Guiavarc'h et al., 2008). From two-year-long measurements of temperature, meridional velocities and SST along $4^{\circ} \mathrm{W}$, Houghton and Colin (1987) suggested that the 15-day oscillations cool the mixed layer significantly in the Gulf of Guinea, in contrast with the net warming due to TIWs in the central and western parts of the equatorial Atlantic.

To understand the respective roles of wind-driven intra-seasonal variability and TIWs in the Tropical Atlantic, Han et al. (2008) studied both signals separately using an ocean general circulation model forced by daily and low-frequency (periods greater than 80 days) QuikSCAT winds respectively. This study, which focused on the variability in a narrow equatorial band between $2^{\circ} \mathrm{S}$ and $2^{\circ} \mathrm{N}$, shows the presence of three distinct intra-seasonal signals near the equator: the first one has periods of between 10 and 40 days and is forced by tropical instabilities; the other two are wind-forced and correspond respectively to eastwardpropagating Kelvin waves (with periods of between 40 and 60 days) and to Yanai waves (with periods of around 15 days) which dominate the variability in the Gulf of Guinea. This study however does not discuss the off-equatorial TIWs that dominate the variability along $5^{\circ} \mathrm{N}$ in detail, nor the possible interaction between TIWs and the wind-forced intra-seasonal variability.

Finally, part of the intra-seasonal variability in winds is also forced by the TIWs themselves. In response to the SST anomalies due to TIWs, atmospheric disturbances are generated and 
are observed as westward-propagating anomalies in wind stress (Chelton et al., 2001; Hashizume et al., 2001), in cloudiness and in precipitation (Caltabiano et al., 2005), at the same spatial and temporal scales as TIWs. These atmospheric disturbances have in turn a negative, though moderate, feedback onto the ocean (Seo et al., 2006). Looking at the phase

relationship between the TIWs and their atmospheric imprints in a coupled ocean-atmospheric simulation of the tropical Atlantic Ocean, Seo et al. (2007) demonstrate that the TIW-induced atmospheric disturbances act to decelerate the TIWs in the near-surface ocean. However this study does not address the possible impact of other sources and periods of intra-seasonal variability in winds on the TIW properties.

This short review of recent literature shows that intra-seasonal wind-driven ocean variability and Tropical Instability Waves have been mostly analyzed separately, and a thorough investigation is needed to understand how they interact with each other in the upper layers of the Atlantic Ocean. The principal aim of this paper is to show that these two signals are of comparable importance to explain the observed SST variability, and that they interact with each other to change the properties of the mixed layer in the western half of the Tropical Atlantic Ocean.

Daily outputs of realistic numerical simulations of the Tropical Atlantic are used to identify the role played by the intra-seasonal variability for the ocean surface conditions. The questions we address in the present paper are: (i) How sensitive is the SST variability to the wind field used as forcing? (ii) What are the respective roles of the 2-20-day wind-forced variability and the 20-50-day TIWs in the Tropical Atlantic upper layers? Firstly, we compare the impact of three different wind products, each with different high-frequency energy, on simulated SST and near-surface velocity in the same ocean model. Then, two additional simulations forced by monthly winds are used in order to filter out the ocean variability due to submonthly wind variability.

\section{Model description and wind data used.}

The model used is the NATL4 configuration of the ocean general circulation NEMO 1.09 model (Madec, 2008; Le Sommer et al., 2009). The model domain is the Atlantic Ocean extending from $25^{\circ} \mathrm{S}$ to $70^{\circ} \mathrm{N}$, with a horizontal resolution of $1 / 4^{\circ}$. It is a subdomain of the global grid presented by Barnier et al. (2006). There are 46 levels in the vertical, 14 of them 
are in the first 200 meters. Ocean bottom topography is based on ETOPO2 (Smith and Sandwell, 1997) in the open ocean, and GEBCO (General Bathymetric Chart of the Ocean) near the shelf. Levitus (1998) data are used to restore temperature and salinity in the sponge layers at the closed boundaries of the domain. Vertical mixing uses a turbulent closure (Blanke and Delecluse, 1993). There is a horizontal biharmonic viscosity and a laplacian isopycnal diffusion of tracers. More details about model parameterizations can be found in Guiavarc'h et al. (2008, 2009).

Radiative fluxes and precipitation from atmospheric reanalyses have large biases, especially in tropical regions. This has led Large and Yeager $(2004,2008)$ to propose an original combination of satellite data and NCEP reanalysis (National Center for Environmental Prediction) to force ocean models. This forcing field, hereafter referred to as LYDS (Large and Yeager dataset), covers years 1958 to 2004, with full interannual variability between 1984 and 2004. Monthly precipitation and daily radiative fluxes are derived from satellite observations. Wind velocity, air temperature and humidity at $10 \mathrm{~m}$ are taken from the NCEP1 reanalysis at $6 \mathrm{~h}$ frequency. Large and Yeager (2004) correct these variables to make them more suitable to force ocean models, and to ensure a good global balance of heat and freshwater. Since NCEP wind velocities are low compared to QuikSCAT (Quik Scatterometer) satellite observations, they are multiplied by a spatially variable factor to bring them in better agreement with QuikSCAT over the recent years (Large and Yeager, 2004). Turbulent fluxes (wind stress, sensible and latent heat flux) are calculated using the bulk formulae recommended by Large and Yeager $(2004,2008)$. Note that the bulk formulae for the wind stress accounts for the surface ocean currents. The present study focuses on years 2000 to 2004 during which satellite SST data are available (Athié and Marin, 2008). The model simulations start in 1995 to enable a 5-year spin-up period prior to the analysis (LYSIM simulation).

In order to analyze the sensitivity of the mixed layer to wind stress, two additional simulations were forced with two different wind fields, QuikSCAT and ERA-40 (QSCAT and ERA40 simulations, respectively). The other atmospheric variables are kept identical in all simulations and the same bulk formulation is used. The QSCAT simulation was forced from 2000 to 2004 by wind measurements from the QuikSCAT fields (www.ifremer.fr/cersat). These data are daily with a spatial resolution of $0.5^{\circ}$. The ERA40 simulation was forced from 2000 to 2001 by ERA-40 winds from the ECMWF reanalysis (European Center for Medium 
range Weather Forecasting). The temporal and spatial resolutions are 6 hours and $1.125^{\circ}$ respectively. Finally, two additional simulations (M-LYSIM and M-QSCAT) were performed from 2000 to 2004 using the monthly-averaged wind stress from LYSIM and QSCAT experiments as forcing, to filter out the oceanic intra-seasonal variability due to submonthly winds. Table 1 summarizes the differences between these five simulations.

Satellite SST data from TMI (TRMM Microwave Image; see Kummerow et al., 1998) and wind velocity records of a PIRATA program mooring (see Servain et al., 1998; Bourlès et al., 2008) at the equator and $23^{\circ} \mathrm{W}$ will be used to validate the model results. SST data are available every day as a 3 -day running average with $0.25^{\circ}$ spatial resolution.

\section{Representation of the TIWs in the NATL4 simulations}

Figure 1 illustrates the typical structure of the intra-seasonal variability SST signature on 29 July 2001 for the TMI satellite data (top panel) and the corresponding NATL4 simulations forced by the different high-frequency wind products (lower panels). In TMI observations, the dominant features are the cusp-shaped undulations of the SST front, which are observed on both sides of the equator near $13^{\circ} \mathrm{W}, 23^{\circ} \mathrm{W}$ and $30^{\circ} \mathrm{W}$. These undulations bring cold waters from the equatorial cold tongue as far as 6 degrees in latitude and bring warm northernhemisphere waters to the equator. They are the SST signature of the TIWs, with wavelengths close to 1000 km (e.g. Caltabiano et al., 2005; Athié and Marin, 2008). The latitude of the TIWs maximum amplitude varies as a function of the observed variable. For SST, TIWs have their higher variability near $1.5^{\circ} \mathrm{N}$ with anomalies reaching $2^{\circ} \mathrm{C}$ (Caltabiano et al., 2005). TIWs can also be found in sea level anomaly data as intense mesoscale structures centered at $5^{\circ} \mathrm{N}$, with amplitudes exceeding $6 \mathrm{~cm}$ (Foltz et al., 2004; Athié and Marin, 2008). In velocity fields, they are observed to be maximum both at the equator and at $3-5^{\circ} \mathrm{N}$ (Weingartner and Weisberg, 1991; Grodsky et al., 2005). Figure 1 (upper panel, left) shows the temporal evolution of TMI SST along $1.5^{\circ} \mathrm{N}$ from May to October 2001. The three undulations mentioned above are seen to propagate westward from about $10^{\circ} \mathrm{W}$ to $25^{\circ} \mathrm{W}$ with phase speeds close to $42 \mathrm{~cm} / \mathrm{s}$ and periods close to 30 days. The duration of the TIWs season is about 3-4 months, starting in June.

The comparison of SST snapshots from TMI observations and NATL4 simulations (Figure 1, right panels) shows that the amplitude and number of undulations along the northern SST 
front differ markedly from one simulation to another on 29 July 2001. In QSCAT, four wellformed cusp-shaped undulations are observed near $8^{\circ} \mathrm{W}, 17^{\circ} \mathrm{W}, 25^{\circ} \mathrm{W}$ and $32^{\circ} \mathrm{W}$, reaching $4^{\circ} \mathrm{N}$ with wavelengths close to $1000 \mathrm{~km}$, in good agreement with TMI observations. On the contrary, the SST signature of TIWs is almost imperceptible in LYSIM and ERA40: only 2 undulations can be identified west of $25^{\circ} \mathrm{W}$ between the equator and $2^{\circ} \mathrm{N}$ and their amplitude and meridional extent are significantly weaker than in TMI observations. The corresponding longitude-time diagrams of SST along $1.5^{\circ} \mathrm{N}$ in 2001 for the three above simulations (Figure 1, left panels) show that these differences remain present during the whole TIW season in 2001. In QSCAT, four westward-propagating cold features are observed from June to September, all originating near $10^{\circ} \mathrm{W}$. The phase speeds, as well as the time of onset and the distance over which TIWs propagate (more than $20^{\circ}$ in longitude), are in good agreement with the TMI observations, even though the exact timing of the cold anomalies associated with TIW events is not reproduced. In contrast, SST diagrams from ERA40 and LYSIM show three undulations from July to October, but less clear and propagating over smaller distance than in TMI data. The westward phase speeds of these undulations are comparable to those estimated from TMI observations in ERA40 and after mid-July, between $30^{\circ} \mathrm{W}$ and $10^{\circ} \mathrm{W}$, in LYSIM. However distinct propagation speeds can be observed from mid-June to mid-August west of $20^{\circ} \mathrm{W}$.

Another remarkable difference between SST observations and the three simulations is the intensity of the cold tongue. On 29 July 2001, waters colder than $21.5^{\circ} \mathrm{C}$ are observed in TMI observations at the equator between $15^{\circ} \mathrm{W}$ and $10^{\circ} \mathrm{W}$. In contrast, SSTs are warmer than $23^{\circ} \mathrm{C}$ near the equator in all simulations west of $10^{\circ} \mathrm{W}$. In addition, the cold tongue in LYSIM is about $1{ }^{\circ} \mathrm{C}$ colder than QSCAT and ERA40. Such variations in the intensity of the cold tongue induce large differences in the temperature of the cold waters that are meridionally advected by TIWs and may explain part of the discrepancies in the amplitude of SST anomalies between the simulations and TMI observations. However, it does not explain why wellformed cusp-shaped undulations of the SST front are present on 29 July 2001 in TMI observations and QSCAT, but not in LYSIM and ERA40.

The above description of TIWs, and the large differences between the TMI observations and the three simulations, is not specific to 2001, as highlighted in time-latitude diagrams of SST along $20^{\circ} \mathrm{W}$ for each year between 2000 and 2004 (Figure 2). This longitude corresponds to the strongest SST anomalies associated with TIWs in TMI observations (Caltabiano et al., 
2005; Athie and Marin, 2008). The large undulations of the SST front north of the cold tongue are observed to extend in latitude from $1^{\circ} \mathrm{N}$ to $4^{\circ} \mathrm{N}$ every year in TMI data, with periods close to 1 month (Figure 2, upper panel). Superimposed to TIWs, one can observe an additional variability with shorter periods (close to 15 days) near the equator (for example in early July 2000 or late July 2002). Unlike TIWs, this second variability seems not to extend beyond $2^{\circ} \mathrm{N}$. Interannual variability in the cold tongue intensity, as well as in the number of waves and in their meridional extent, can also be observed.

The comparison of TMI observations and numerical simulations along $10^{\circ} \mathrm{W}$ (Figure 2) confirms that (i) the cold tongue is significantly warmer in the simulations than in the observations and (ii) the undulations of the SST front north of the equator are mostly weaker in the simulations than in the observations, except for the large TIW events of late July 2000 and early July 2004. Interestingly, the large northward penetrations of waters from the cold tongue beyond $3^{\circ} \mathrm{N}$ are found every year in QSCAT (as in TMI observations), but only in 2000 and 2004 in LYSIM. In 2001, 2002 and 2003 in LYSIM, the undulations of the SST front are found to be significantly weaker, leading to moderate north-south migrations of the SST front (less than $1^{\circ}$ in latitude), with shorter periods (close to 15 days) than the TIWs.

The meridional migrations of the SST front mainly result from the presence of intense meridional velocities, as illustrated by the time-latitude diagrams of surface meridional velocities for the three simulations (Figure 3). Two distinct latitudes of variability can be observed, in agreement with the literature (e.g. Weingartner and Weisberg, 1991; Grodsky et al., 2005): the first one is equatorially-trapped (between $2^{\circ} \mathrm{S}$ and $1^{\circ} \mathrm{N}$ ), and the second one has maximum velocities off equator (between $2^{\circ} \mathrm{N}$ and $5^{\circ} \mathrm{N}$ ). As in SST, an additional variability with a 15-day period is present at the equator, especially in LYSIM. Near-equatorial anomalies have similar amplitude in QSCAT and in LYSIM (30-40 cm/s), with some evidence of an interannual variability. In contrast, the northern-hemisphere intra-seasonal variability is lower in LYSIM (10-30 cm/s) than in QSCAT (30-40 cm/s), except in 2000 where anomalies in LYSIM exceeded $60 \mathrm{~cm} / \mathrm{s}$. In ERA40, the TIWs amplitude is weaker than in LYSIM and QSCAT both at the equator (between 20 and $30 \mathrm{~cm} / \mathrm{s}$ ) and in the northern hemisphere (about $10 \mathrm{~cm} / \mathrm{s}$ ). Time-longitude diagrams at $3.5^{\circ} \mathrm{N}$ (not shown) reveal that TIWs propagate westward at comparable phase velocities (about $40 \mathrm{~cm} / \mathrm{s}$ ) in all simulations, indicating that TIW phase speeds are largely independent of the wind product used. Another remarkable difference between the time variabilities in both SST and surface meridional 
velocities along $3.5^{\circ} \mathrm{N}$ is the presence of high-frequency variability (less than 1 week) in surface velocities, which was particularly strong west of $8^{\circ} \mathrm{W}$ during 2001 in LYSIM. This high-frequency variability is not apparent in Figure 3 where a 7-day running average has been applied.

Velocity observations in the Tropical Atlantic ocean from Weisberg and Weingartner (1988; their Figures 6 and 7) show that the maximum eddy kinetic energy (EKE) associated with TIWs, ranges between 1300 and $1800 \mathrm{~cm}^{2} / \mathrm{s}^{2}$ at the surface, and decreases with depth to about $400-800 \mathrm{~cm}^{2} / \mathrm{s}^{2}$ at $100 \mathrm{~m}$ depth. EKE at intra-seasonal timescales (Figure 4) was computed for all above simulations following

$$
E K E=\left(\left\langle u^{\prime} u^{\prime}\right\rangle+\left\langle v^{\prime} v^{\prime}\right\rangle\right) / 2
$$

where primes denote the 2-50 day Fourier components of the horizontal velocity, and brackets denote 31-day running averages.

Figures $4 \mathrm{a}$ and $4 \mathrm{~b}$ show the EKE for the three simulations at $28^{\circ} \mathrm{W}$ and the equator at $10 \mathrm{~m}$ and 100m depths. As in Weisberg and Weingartner (1988), EKE diminishes significantly from the surface down to $100 \mathrm{~m}$, even though EKE is twice as weak in the model than in the observations at these two depths. In general, EKE reaches its maximum in summer (JuneAugust), with a secondary maximum some years in fall, in good agreement with Weisberg and Weingartner (1988). A strong interannual modulation of the 2-50 day variability is found in both QSCAT and LYSIM, but does not coincide in the two simulations. Such an interannual variability was not evident in Weisberg and Weingartner (1988) due to the limited duration of their time series (1 or 2 years), but has already been reported from SST and sea level anomalies observations (Caltabiano et al., 2005; Athie and Marin, 2008). In addition, the time variability of EKE differs largely between the surface and the 100m depth from one simulation to another, indicating two different behaviors near the surface (where intraseasonal variability is strongest in QSCAT) and at 100m depth (where LYSIM is the most energetic at periods lower than 50 days). EKE is found, in 2000 and 2001, to be weaker in ERA40 than in QSCAT or LYSIM, both at the surface and at 100m depth.

The comparison of EKE time evolution at $28^{\circ} \mathrm{W}$ between the equator and $3^{\circ} \mathrm{N}$ near the surface (Figures 4a and 4c) shows that intra-seasonal EKE does not coincide at these two latitudes. EKE experiences intense interannual variability at $3^{\circ} \mathrm{N}$ as it does at the Equator, but 
the strongest events are not systematically present at the same time at these two latitudes. This is demonstrated for example in August 2001 or 2004 when EKE maxima at the equator had no counterpart at $3^{\circ} \mathrm{N}$ in LYSIM, or in December 2001 when intense EKE maximum at $3^{\circ} \mathrm{N}$ had no equivalent at the equator in QSCAT. Along the equator, intra-seasonal EKE has comparable time evolution at $28^{\circ} \mathrm{W}$ and $15^{\circ} \mathrm{W}$ in all simulations (Figures $4 \mathrm{a}$ and $4 \mathrm{~d}$ ), but proves to be significantly lower at $4^{\circ} \mathrm{W}$ (Figure 4e), in agreement with Weisberg and Weingartner (1988). This behavior is consistent with the predominance of TIWs variability west of $10^{\circ} \mathrm{W}$.

In our model, the surface signature of intra-seasonal variability in SST, surface meridional velocity and EKE thus strongly depends on the choice of the wind product. The wind forcing has an impact on the number and amplitude of TIWs, as well as their meridional extent and the distance over which they propagate westward. Simulations forced by LYDS and, in a lesser extent, ERA-40 do not reproduce the cusp-shaped SST signature of TIWs north of the equator, even though their period, wavelength and phase speed are comparable with the observations in all simulations.

Two distinct mechanisms may explain the discrepancies in the surface signature of TIWs in our simulations. Firstly, the distinct seasonality of each wind product may give rise to a different seasonal evolution of equatorial surface and subsurface currents. Such differences in the current system could cause different intraseasonal variability triggered by tropical instabilities. Secondly, the intra-seasonal variability in the near-surface ocean velocities may be directly altered by changes in the spatial distribution and amplitude of intra-seasonal variability in the winds.

To assess the respective roles of these two potential mechanisms, we first present the horizontal distributions of mean surface zonal currents for the three simulations (Figure 5) in boreal summer (June-August), when TIWs are most active. These currents have been computed for the period 2000-2001, when LYDS, QuikSCAT and ERA-40 winds are all available, but the results are quite similar in LYSIM and QSCAT when the full period (20002004) is considered (not shown). In QSCAT, the surface circulation is dominated by the South Equatorial Current (SEC), flowing westward between $8^{\circ} \mathrm{S}$ and $4^{\circ} \mathrm{N}$, the North Equatorial Countercurrent (NECC) flowing eastward north of $4^{\circ} \mathrm{N}$ and west of $10^{\circ} \mathrm{W}$, and the Guinea Current (GC) flowing eastward north of $4^{\circ} \mathrm{N}$ in the Gulf of Guinea, east of $10^{\circ} \mathrm{W}$. 
Velocities during this season are found to exceed $45 \mathrm{~cm} / \mathrm{s}$ for the SEC from $30^{\circ} \mathrm{W}$ to $0^{\circ} \mathrm{E}$ along $2^{\circ} \mathrm{N}, 25 \mathrm{~cm} / \mathrm{s}$ for the NECC near $6^{\circ} \mathrm{N}$ and $60 \mathrm{~cm} / \mathrm{s}$ for the GC near $6^{\circ} \mathrm{W}-4^{\circ} \mathrm{N}$. These surface currents are in good agreement with the boreal summer observations by Richardson and McKee (1984) and generate intense meridional shears that will be subject to tropical instabilities (Philander, 1976, 1978; Qiao and Weisberg, 1998).

The anomalies in the boreal summer surface currents with ERA40 and LYSIM, when compared to QSCAT, are shown in Figure 5. West of $10^{\circ} \mathrm{W}$, both simulations lead to westward anomalies between $4^{\circ} \mathrm{S}$ and $3^{\circ} \mathrm{N}$ (of the order of 5-10 cm/s for ERA40 and 10-20 $\mathrm{cm} / \mathrm{s}$ for LYSIM). North of $3^{\circ} \mathrm{N}$, the situation is more complex. In LYSIM, eastward anomalies are found between $3^{\circ} \mathrm{N}$ and $7^{\circ} \mathrm{N}$ (of the order of $5-15 \mathrm{~cm} / \mathrm{s}$ ) and westward anomalies beyond $7^{\circ} \mathrm{N}$. In ERA40, eastward anomalies $(\sim 5 \mathrm{~cm} / \mathrm{s})$ are still found between $3^{\circ} \mathrm{N}$ and $5^{\circ} \mathrm{N}$, but anomalies are westward north of $5^{\circ} \mathrm{N}$. Thus, the NECC along $6^{\circ} \mathrm{N}$ is intensified in LYSIM, but weakened in ERA40. If the weak NECC amplitude compared with QSCAT is a possible reason for the weak TIWs in ERA40, the NECC intensification in LYSIM cannot explain the unrealistic TIWs observed in this simulation. In addition, in LYSIM as in ERA40, the SEC is reinforced near the equator and the NECC extends slightly more towards the equator than in QSCAT. The meridional shear of surface zonal currents is then increased in both LYSIM and ERA40 when compared to QSCAT. This should lead to stronger instabilities, which is not consistent with the smaller observed TIWs amplitudes in these two simulations. In the subsurface layer, the Equatorial Undercurrent (EUC) across $23^{\circ} \mathrm{W}$ in boreal summer is similar in all three simulations, though perhaps slightly more intense in QSCAT (a 10\% stronger EUC core).

Two additional simulations, forced by LYDS winds, have been performed to explore the role of the seasonal current background state for the development of TIWs. The first one differs from LYSIM by the use of a biharmonic diffusion rather than a laplacian isopycnal diffusion: this does not affect the TIW amplitude. The second simulation differs from LYSIM by a weaker viscosity, which led to a slight intensification of the EUC. The SST signature of TIWs was slightly intensified in this simulation, but remained weaker than in TMI data.

In order to evaluate the role of the high frequency in winds over the TIWs development, two additional simulations forced by monthly-averaged LYDS and QuikSCAT wind stress were performed from 2000 to 2004 (Table 1; Figure 6). Surprisingly, the SST signature of TIWs is 
significantly enhanced each year in the absence of submonthly wind forcing in the case of LYDS winds, and to a lesser extent for QuikSCAT winds. Large SST undulations are now present each year in M-LYSIM, all extending beyond 3º (even in 2001, 2002 and 2003 where no such undulations were seen in LYSIM). The same conclusion applies most years to M-QSCAT. Unlike LYSIM, the north-to-south migrations of the SST front in M-LYSIM are now stronger each year than in the TMI observations (Figure 2).

As for SST, the meridional velocities associated with TIWs are significantly stronger in the absence of submonthly wind variability (compare Figure 6 and Figure 3). The two latitudes of maximum intra-seasonal variability (equator and $3^{\circ} \mathrm{N}$ ) are still present, while no submonthly upper ocean variability can be observed (no time filtering has been applied to meridional velocities in Figure 6). Meridional velocities now have comparable amplitudes in M-LYSIM and M-QSCAT, both at the equator $(\sim 50 \mathrm{~cm} / \mathrm{s})$ and north of the equator (between 60 and 80 $\mathrm{cm} / \mathrm{s}$ ). In contrast, the westward phase speeds associated with TIWs are comparable (close to $40 \mathrm{~cm} / \mathrm{s}$ ) in LYSIM and M-LYSIM (not shown). These results thus provide strong evidence that the submonthly variability in LYDS winds is mainly responsible for the weak TIWs surface signature in LYSIM, both in SST and in meridional velocities, particularly in 2001, 2002 and 2003.

\section{Distribution of the submonthly variability in wind stress and in surface ocean currents.}

In the previous section we have demonstrated the sensitivity of the ocean surface conditions to the wind field used as forcing in the NATL4 model. At intra-seasonal time scales, the ocean variability directly forced by the wind was shown to significantly alter the TIWs surface signature in SST and meridional velocity. This indicates that some differences in the high frequency winds between QuikSCAT, LYDS and ERA-40 datasets are the most likely candidates to explain the changes in the surface signature of TIWs between the three simulations. To determine how the submonthly variability differs between QSCAT, LYSIM and ERA40 simulations, we now analyze the energy distribution at periods lower than 50 days in the wind stress and in the ocean surface velocities for each simulation.

A continuous time series of wind measurements is available from the PIRATA program mooring at the equator and $23^{\circ} \mathrm{W}$ from February 2000 to March 2004. The wind spectra from 
PIRATA, LYDS, QuikSCAT and ERA-40 at the same location are shown in Figure 7 for the periods 2000-2001 (including ERA-40 winds) and 2000-2003 (without ERA-40 winds). At periods less than 30 days, three frequency ranges of maximum variability are found near 4-5, 7 and 13 days in most products. In the 2-20 day frequency band, PIRATA, QuikSCAT and ERA-40 winds have comparable energy, whereas the LYDS wind is far more energetic.

The horizontal distribution of the wind stress variance at periods between 2 and 10 days in 2000-2001 shows two maxima located between 2 and 8 degrees north and south of the equator in the western Atlantic for the three data sets (Figure 8). However LYDS wind stress contains higher variance in this frequency band, especially west of $15^{\circ} \mathrm{W}$ near the equator, where energy is almost zero in QuikSCAT and ERA-40. Between $2^{\circ} \mathrm{N}$ and $5^{\circ} \mathrm{N}$, west of $10^{\circ} \mathrm{W}$, in the region where off-equatorial TIWs take place, the variance maximum in LYDS is slightly displaced towards the equator (south of $4^{\circ} \mathrm{N}$ ), when compared to QuikSCAT and ERA-40 wind stress. The maximum variance in LYDS or QuikSCAT winds corresponds to a variability centered around a period of 4.5 days and that is present in boreal summer every year, concomitantly with TIWs. This variability at 3-6 days is known as African Easterly Waves and has been observed in the atmosphere propagating to the west (Pytharoulis and Thorncroft, 1998; Fyfe, 1999). Note moreover the presence of additional small-scale structures in the QuikSCAT variance distribution: they are the signature of intense smallscale day-to-day variability that is partly due to noise in the QuikSCAT winds in the presence of rain. Finally, ERA-40 wind stress has the weakest variance in the 2-10 day frequency band over the whole tropical Atlantic, with a spatial distribution that is comparable to QuikSCAT but with about half the amplitude.

In contrast, for the longer period bands (10-20 day and 20-50 day), the three wind stress fields have similar variance distribution, even though ERA40 is again less energetic than LYDS and QSCAT. Variances almost vanish along the equator and increase poleward both North and South of the equator. However, as for the 2-10 day frequency band, wind stress variances in the 10-20 day frequency band are somewhat stronger in LYDS than in QSCAT, particularly near $3^{\circ} \mathrm{N}$ in the center of the basin and near $4^{\circ} \mathrm{S}$ west of $20^{\circ} \mathrm{W}$.

The LYDS winds are derived from the global NCEP Reanalysis, in which some biases have been reported in the literature and attributed to the bulk algorithms used, as well as to the state variables themselves (Smith et al., 2001). Firstly, the low spatial resolution of NCEP 
atmospheric fields $\left(2.5^{\circ}\right)$, when compared to QuikSCAT wind fields $\left(0.5^{\circ}\right)$, may explain the larger spatial patterns of high-frequency winds in the case of LYDS winds. Secondly, the spatially-dependent multiplicative factor applied by Large and Yeager (2008) to NCEP winds is greater than 1 over a large equatorial region extending from $5^{\circ} \mathrm{S}$ and $10^{\circ} \mathrm{N}$, exceeding 1.4 north of the equator (their Figure 6). Such a large factor (applied at all frequencies) may be an additional cause for the observed spurious extension of off-equatorial high-frequency winds towards the equator. This is confirmed by the examination of the wind power spectral density of uncorrected NCEP1 winds at $23^{\circ} \mathrm{W}-0^{\circ} \mathrm{N}$, which, unlike LYDS, has similar amplitude in the 2-10 day frequency band to those in PIRATA, QuikSCAT or ERA-40.

Figure 9 shows three dramatically different patterns of EKE at the surface of the ocean in three different frequency bands: 2-10 days, 10-20 days and 20-50 days. A similar analysis was performed in the Gulf of Guinea, east of $5^{\circ} \mathrm{W}$, in Guiavarc'h et al. (2009).

In the 2-10 day frequency band, the EKE distribution is similar in all simulations: large EKE is seen on each side of the equator (near $4^{\circ} \mathrm{S}$ and $4^{\circ} \mathrm{N}$ ) over the whole width of the equatorial basin. EKE maxima are found in two distinct longitude bands, in the center of the basin (between $25^{\circ} \mathrm{W}$ and $10^{\circ} \mathrm{W}$ ) and in the eastern half of the Guinea Gulf (east of $0^{\circ} \mathrm{E}$ ). However, the relative amplitudes of these maxima vary from one simulation to another. In LYSIM, the EKE (exceeding $90 \mathrm{~cm}^{2} / \mathrm{s}^{2}$ ) is about twice stronger than in QSCAT and ERA40, and located north of the equator between $30^{\circ} \mathrm{W}$ and $10^{\circ} \mathrm{W}$, i.e. in the region where the off-equatorial TIWs are observed. East of $0^{\circ} \mathrm{E}$, the variance has comparable magnitude both north and south of the equator in all simulations. This signal is compatible with the latitudinal structure, characteristic periods and eastward group velocity of inertia-gravity waves. Such waves have already been described in the literature, with two distinct peaks in the 2-10 day frequency band : one at 7 days (Wainer et al., 2003; Bunge et al., 2006) and the other at 4.5 days (Garzoli, 1987). Both the 2-10 day wind forcing, and its oceanic response, are maximum off the equator.

On the contrary, the second signal between 10 and 20 days is equatorially-trapped, even though the corresponding wind variability is strongest off the equator (poleward of $4^{\circ}$ in latitude). As in the 2-10 day frequency band, large values of the 10-20 day energy are seen over the whole width of the basin, with larger amplitudes west of $5^{\circ} \mathrm{W}$ in LYSIM (exceeding $100 \mathrm{~cm}^{2} / \mathrm{s}^{2}$ ) than in QSCAT and ERA40. At those frequencies, the only modes of variability 
in the ocean are Yanai and Kelvin waves, for which energy propagates to the east. This explains why the 10-20 day variability in the ocean is present all along the equator, while the wind at those frequencies is strongest in the western side of the basin. Evidences of such 15day Yanai waves have been found in observations (Houghton and Colin, 1987; Bunge et al., 2006; Guiavarc’h et al., 2008). Note that M-QSCAT and M-LYSIM present almost no energy in both 2-10 day and 10-20 day frequency bands (not shown), indicating as in Han et al. (2008) and Guiavarc'h et al (2008) that the submonthly variability is essentially forced by the intra-seasonal variability in the wind forcing.

$\mathrm{EKE}$ at periods of between 20 and 50 days is maximum near the equator, west of $10^{\circ} \mathrm{W}$, extending from $2^{\circ} \mathrm{S}$ to $5^{\circ} \mathrm{N}$ with a comparable geographical pattern in all three simulations. EKE is highest in QSCAT $\left(200 \mathrm{~cm}^{2} / \mathrm{s}^{2}\right)$, with weaker magnitude in LYSIM $\left(150 \mathrm{~cm}^{2} / \mathrm{s}^{2}\right)$ and ERA40 $\left(110 \mathrm{~cm}^{2} / \mathrm{s}^{2}\right)$ simulations. These results based on EKE agree with previous conclusions deduced from SST (Section 3). Note that the EKE maximum is about twice larger in the 20-50 day than in the 2-10 day or 10-20 day frequency bands, whereas the reverse was true for the wind stress variance (Figure 8). This indicates that most of the 20-50 day variability is not forced by wind variability at the same frequencies, but by tropical instabilities.

The weaker EKE associated with TIWs in LYSIM, when compared to QSCAT, thus coindices with stronger oceanic variability at periods lower than 10 days in LYSIM. This 2-10 day variability takes place in the same region as off-equatorial TIWs and is thought to result from the more equatorward extension of the wind variability at the same periods in the center of the basin (near $20^{\circ} \mathrm{W}$ ). The LYSIM simulation will thus experience the strongest interaction, if any, between TIWs and wind-forced 2-10 day variability. This suggests that the differences in the SST signature of TIWs between the simulations presented in this study are mostly due to differences in upper ocean dynamics at intra-seasonal timescales, even though oceanatmosphere fluxes or the intensity of the cold tongue may also play a role. It has been checked that the horizontal distribution of the estimated variance in wind stress and in surface velocities in LYSIM and QSCAT are quite similar when the full period 2000-2004 is used. 


\section{Influence of the wind-forced intra-seasonal variability over TIWs in the upper ocean.}

Until now, we have analysed the distribution of the high frequency variability only at the surface of the ocean and shown that the submonthly variability forced by the wind was the most likely candidate to explain the unrealistic weak SST signature of TIWs in LYSIM. In this section, the relationship between these two ocean variabilities will be explored in more detail. First the subsurface structure of the off-equatorial TIWs and the submonthly windforced variability will be described. Then the interannual variability of TIWs will be discussed in the light of the temporal modulation of the submonthly wind-forced variability.

\section{Subsurface signature of TIWs}

The time-depth diagrams of meridional velocity in 2000 at $23^{\circ} \mathrm{W}$ and $3.5^{\circ} \mathrm{N}$, where the offequatorial TIWs signature is largest (Figure 3), shows the subsurface signature of TIWs from July to September as the succession of positive and negative anomalies, with periods close to 1 month (Figure 10). Two distinct regions of variability can be identified from the comparison of the various simulations. The first one takes place between the base of the mixed-layer and the $20^{\circ} \mathrm{C}$ isotherm (D20), and is dominated by TIWs, with strong meridional velocities (greater than $40 \mathrm{~cm} / \mathrm{s}$ ) and large vertical displacements of the thermocline. The second one is confined to the surface mixed layer, where TIWs are generally weaker and superimposed on submonthly variability with periods less than 1 week (Figure 10). Although the variability beneath the mixed-layer has comparable amplitudes and structures in all simulations, this is not the case in the surface mixed-layer where both TIWs and submonthly variability are found to strongly depend upon the wind forcing used. For instance, 2 distinct TIWs undulations can be identified in LYSIM and QSCAT from July to September, while only one is found in ERA40 (in August). In contrast, in M-LYSIM where submonthly wind variability has been filtered out, the TIWs season lasts longer, from June to late September, and the number of TIWs events is greater, with 4 distinct maxima of positive meridional velocity exceeding 40 $\mathrm{cm} / \mathrm{s}$ during this period. In particular, meridional velocities associated with TIWs have similar magnitudes in the mixed-layer and beneath the mixed-layer. This indicates that the submonthly variability strongly alters the vertical structure of TIWs and significantly decreases their amplitude within the mixed-layer. It is important to observe that there is no variability with periods lower than 20 days in M-LYSIM at this location, indicating once again that surface variability at these periods is entirely forced by submonthly winds. Note 
that (i) the meridional velocities associated with TIWs in the mixed-layer and beneath the mixed-layer are found to be time-lagged in all simulations, in the presence and in the absence of submonthly variability in winds, and (ii) TIWs become progressively stronger and deeper beneath the mixed-layer from mid-June to September. It is not clear whether this time-lag results from the vertical propagation of equatorial waves, or from the superimposition of two distinct signals beneath and above the base of the mixed-layer.

In all simulations, TIWs north of the equator are found to be associated with large vertical displacements of the thermocline $(\sim 30 \mathrm{~m})$ and of the mixed layer base $(\sim 40 \mathrm{~m})$ with an apparent out-of-phase relationship, especially in presence of strong meridional velocities. More specifically, the $20^{\circ} \mathrm{C}$ isotherm deepens (resp. shallows) and the mixed layer base shallows (resp. deepens) in the presence of northward (resp. southward) velocities. A threedimensional structure for off-equatorial TIWs, implying intense vertical movements in the upper ocean, has already been evidenced from in situ observations (Menkès et al., 2002). This is also discussed in the case of the Pacific Ocean by Menkès et al. (2006), who emphasize the potential role of such TIW-induced variations of the mixed layer depth for the mixed-layer heat budget. In that study, the authors relate the vertical motion of the mixed layer base to the meridional advection of surface waters across the SST front that delimits the equatorial cold tongue north of the equator (their figure 2). This implies for instance subduction of surface equatorial cold waters under warmer surface waters north of the front when velocities are northward. Note finally that the mixed-layer depth in M-LYSIM presents intense highfrequency variability in boreal summer, for instance in early August (Figure 10). Since submonthly winds are absent in this simulation, this indicates that the strong vertical shears due to TIWs are likely to generate high-frequency variability in the dynamics of the mixedlayer.

\section{Interannual variability}

Let us now consider the long-term time evolution of surface mean EKE for the 2-20 day wind forced variability and the TIWs signal (Figure 11), and their possible interaction throughout the period of the study (2000-2004). In LYSIM (Figure 11a), the EKE at TIWs timescales is intensified in the boreal summer of most years, with the highest amplitude in 2000 (310 $\mathrm{cm}^{2} / \mathrm{s}^{2}$ ) and minimum activity in summers 2001 and 2002 (lower than $160 \mathrm{~cm}^{2} / \mathrm{s}^{2}$ ), when TIWs have almost no energy. In contrast, the 2-20 day signal does not exhibit a clear seasonal 
behavior. However, during spring of most years, just before the appearance of TIWs, the 2-20 day energy slightly increases and reaches comparable values to the 20-50 day EKE boreal summer maximum. In particular, 2001 and 2002 are the years when TIWs are particularly weak in LYSIM and when significant energy is found in the 2-20 day frequency band over a long-term period (about 6 months from February to July). In addition, one important result is that the boreal summer peak in 20-50 day EKE, when it exists, barely exceeds the 2-20 day energy, so that TIWs are not significantly stronger than the background submonthly upper ocean variability.

The same computation was performed for M-LYSIM (Figure 11a, grey line). EKE (for periods between 2 and 50 days) presents the same seasonal evolution as for 20-50 day EKE in LYSIM, but the boreal summer intensification is present every year and reaches far larger amplitudes (always greater than $250 \mathrm{~cm}^{2} / \mathrm{s}^{2}$ ). EKE is at a maximum in 2004 (between 400 and $600 \mathrm{~cm}^{2} / \mathrm{s}^{2}$ ), and at a minimum in 2002 (lower than $350 \mathrm{~cm}^{2} / \mathrm{s}^{2}$ ), thus revealing a different interannual variability from LYSIM. The presence of submonthly wind variability has thus two major impacts: (i) it significantly decreases the amplitude of the 20-50 day ocean surface variability and (ii) it provides high-frequency variability in the upper ocean that is as strong or even stronger in some years, than the TIWs.

Figure 11b presents the corresponding EKE time evolution for QuikSCAT winds. Contrary to the LYSIM simulation, the boreal summer EKE maximum is present every year both in QSCAT and M-QSCAT for periods lower than 50 days. Moreover the difference in amplitudes of the EKE boreal summer maximum between the simulations in the presence, and in the absence, of submonthly winds is significantly weaker in QSCAT than in LYSIM. These differences can be explained by the presence every boreal summer of a maximum in 20-50 day EKE that is stronger than the 2-20 day EKE. However, as in LYSIM and M-LYSIM, different interannual variabilities are observed in QSCAT and M-QSCAT, confirming that part of the TIWs interannual variability still depends upon the submonthly wind forcing.

These results strongly suggest that the wind-forced intra-seasonal variability in the ocean upper layers systematically decrease the amplitude of the TIWs surface signature, thus being able to significantly contribute to the interannual variability of TIWs at the surface of the Atlantic Ocean. However, the fact that the interannual variabilities in M-LYSIM and MQSCAT do not coincide (Figure 11) indicates that other factors, such as the interannual 
variability of seasonal currents or the cold tongue intensity (Caltabiano et al., 2005), or the differences in the phase relationship between TIWs and their atmospheric imprints in our numerical simulations (Seo et al., 2007), must also play a role for the interannual modulation of TIWs (Caltabiano et al., 2005).

\section{Summary and conclusions}

This work underlines the importance of the wind-forced intra-seasonal variability for the nearsurface ocean conditions of the Equatorial Atlantic. Three parallel simulations forced by different wind fields (LYDS, QuikSCAT and ERA-40) were compared to evaluate the sensitivity of the upper ocean intra-seasonal variability to the wind. It is shown that the surface characteristics of the ocean at intra-seasonal timescales strongly depend on the wind field used as forcing. In particular, the amplitude of the TIWs, their meridional extent and the different stages of their development and propagation, are found to differ largely from one simulation to another from both SST and EKE fields. The comparison of mean boreal summer zonal currents in the upper Atlantic Ocean along $23^{\circ} \mathrm{W}$ between the three simulations shows that the weak TIW signature observed in LYSIM does not come from the low frequency of the LYDS winds.

The comparison between observations and simulations shows that (i) the intensity of the boreal summer cold tongue is significantly weaker in the model and (ii) the intra-seasonal EKE is too weak (at least 50\%) compared to the mooring observations. One possible explanation would be that dynamic EKE production in the model is underestimated, thus leading to a relative overestimation of the wind-forcing effect. However the comparison of simulations forced by LYDS and QuikSCAT winds, and their monthly averages, provides strong evidence that the upper ocean variability at periods between 2 and 20 days is entirely forced by the wind and is the most probable cause for the weak TIWs amplitude at the surface. In contrast, the less intense NECC in ERA40 in boreal summer might explain the low amplitude of TIWs observed in this simulation.

The distribution of the wind stress energy, as well as the EKE at the surface of the ocean, has been analyzed. LYDS wind energy is especially strong in the 2-10 day frequency band when compared with PIRATA mooring measurements at $0^{\circ} \mathrm{N}, 23^{\circ} \mathrm{W}$ or with QuikSCAT and ERA40 wind fields. The wind stress variability between 2 and 20 days forces ocean variability and 
gives rise to two distinct signals: (i) equatorially-trapped Yanai waves between 10 and 20 days and (ii) off-equatorial inertia-gravity waves in the 2-10 day frequency range. The strong energy of LYDS winds in the 2-10 day band thus leads to more intense wind-forced intraseasonal variability in the upper ocean at the same latitudes as off-equatorial TIWs. Such wind-forced variability interacts with TIWs in the ocean surface mixed-layer by significantly decreasing their amplitude and, in some cases, by making them almost disappear, as it has been proven in this study for 2001 .

Two regions of distinct behaviours were identified for ocean intra-seasonal variability above the thermocline from our simulations. In the mixed layer, wind-forced signals as well as TIWs both contribute to the intra-seasonal variability, whereas TIWs dominate beneath the mixed layer. Furthermore the differences in the interannual variability of the TIWs amplitude in simulations forced by high temporal resolution or monthly-averaged winds, suggest that the wind-forced submonthly ocean variability could be responsible for part of the year-to-year TIWs variability. More studies are needed to better understand the causes of interannual changes in the TIWs characteristics and their impact on the surface properties of the tropical Atlantic Ocean. In particular, a coupled ocean-atmosphere simulation of the tropical Atlantic Ocean, in which the intra-seasonal wind variability that is not due to TIWs would be filtered out, would help to quantify the respective roles of the coupled response to TIWs and the internal atmospheric variability for the TIWs properties at the surface of the tropical Atlantic.

The results of the present paper mainly rely on the comparison of numerical simulations forced by winds including, or not, the submonthly variability. In QSCAT, LYSIM and ERA40, the wind stress forcing is computed from wind velocity fields through a bulk formulation that accounts for surface ocean currents. In M-QSCAT and M-LYSIM, the wind stress forcing is directly provided by the monthly-averages of the wind stress fields in QSCAT and LYSIM. This different strategy to force the ocean model in M-QSCAT and MLYSIM was necessary to filter out the submonthly wind stress variability without changing the low-frequency wind stress variability, but its impact on the near-surface ocean variability would require more investigation. For instance, Eden and Dietze (2009) show that using the air-sea velocity difference (instead of the atmospheric wind) in the wind stress bulk parameterization dampens the near-surface eddy activity, especially in the tropical Atlantic. 
In addition, such wind forced simulations do not include the potential effect of oceanatmosphere coupling onto TIWs. Seo et al. (2007) show that the atmospheric disturbances associated with TIWs act to decelerate the TIWs in a coupled ocean-atmosphere model of the tropical Atlantic Ocean. In a forced ocean model, on the contrary, TIWs and their atmospheric imprints are fully decoupled. As discussed by these authors, this should randomly alter the phase relationship between TIWs and their atmospheric imprints, and induce spurious dampening or strengthening of TIWs. However, in our simulations, the energy of TIWs is systematically weaker in the presence of submonthly winds than for monthly-averaged winds, both with LYDS (Figure 11a) and QuikSCAT (Figure 11b). This suggests that the coupled ocean-atmosphere response to TIWs is not the only one that controls their amplitude.

In this paper we have demonstrated that the ocean variability at intra-seasonal timescales strongly depends on the amplitude of the high-frequency wind fluctuations. The choice of the wind forcing is thus crucial to represent realistic surface ocean conditions in the equatorial Atlantic. In particular, wind fields containing strong energy at high frequencies, specifically in the inertia-gravity frequency band, are thought to have a spurious impact on the surface mixed layer properties and on the SST. These results have potentially important consequences for the surface mixed-layer heat budget, and then for the SST and the ocean-atmosphere heat fluxes. Such relation between the high-frequency (submonthly) winds and TIWs needs to be further explored in tropical oceans.

\section{Acknowledgements}

Support for this study was provided by CNES, Groupe Mission Mercator-Coriolis (GMMC) and CONACyT. TMI data were produced by Remote Sensing Systems and sponsored by the NASA Earth Science REASon DISCOVER Project. TMI data are available at http://www.remss.com. Numerical simulations have been run at the IDRIS computing centre (CNRS, Orsay, France), with the help of the DRAKKAR project team. 


\section{References}

Athié, G., Marin, F., 2008. Cross-equatorial structure and temporal modulation of Intraseasonal variability at the surface of the Tropical Atlantic Ocean. Journal of Geophysical Research, doi:10.1029/2007JC004332.

Barnier, B., Madec, G., Penduff, T., Molines, J.-M., Treguier, A.-M., Le Sommer, J., Beckmann, A., Biastoch, A., Böning, C., Dengg, J., Derval, C., Durand, E., Gulev, S., Remy, E., Talandier, C., Theetten, S., Maltrud, M., McClean, J., De Cuevas B., 2006. Impact of partial steps and momentum advection schemes in a global circulation model at eddy permitting resolution. Ocean Dynamics 56(5-6), 543-567, doi:10.1007/s10236-006-0082-1.

Baturin, N.G., Niiler, P.P., 1997. Effects of instability waves in the mixed layer of the equatorial Pacific. Journal of Geophysical Research, 102, 27 771-27 793.

Blanke, B., Delecluse P., 1993. Variability of the tropical Atlantic ocean simulated by a general circulation model with two different mixed layer physic. Journal of Physical Oceanography 23, 1363-1388.

Bourlès, B., Lumpkin, R., McPhaden, M.J., Hernandez, F., Nobre, P., Campos, E., Yu, L., Planton, S., Busalacchi, A.J., Mourra, A.D., Servain J., Trotte, J., 2008. The PIRATA Program: History, Accomplishments, and Future Directions. Bulletin of the American Meteorological Society 89, 1112-1125.

Bunge, L., Provost, C., Lilly, J., d'Orgeville, M., Kartavtseff, A., Melice, J.L., 2006. Variability of the Horizontal Velocity Structure in the Upper $1600 \mathrm{~m}$ of the Water Column on the Equator at $10^{\circ} \mathrm{W}$. Journal of Physical Oceanography 36, 1287-1304.

Bunge, L., Provost, C., Kartavtseff, A., 2007. Variability in horizontal current velocities in the central and eastern equatorial Atlantic in 2002. Journal of Geophysical Research 112(C02014). doi:10.1029/2006JC003704.

Caltabiano, A.C.V., Robinson, I.S., Pezzi, L.P., 2005. Multi-year satellite observations of instability waves in the Tropical Atlantic Ocean. Ocean Science 1, 97-112.

Chelton, D.B., Esbesen, S.K., Schlax, M.G., Thum, N., Freilich, M.H., Wentz, F.J., Gentemann, C.L., McPhaden, M.J., Schopf, P.S., 2001. Observations of Coupling between Surface Wind Stress and Sea Surface Temperature in the Eastern Tropical Pacific. Journal of Climate 14, 1479-1498.

Düing, W., Hisard, P., Katz, E., Knauss, J., Meincke, J., Miller, L., Moroshkin, K., Philander, G., Rybnikov, A., Voigt, K., Weisberg, R., 1975. Meanders and long waves in the equatorial Atlantic. Nature 257, 280-284.

Eden, C., Dietze, H., 2009. Effects of meso-scale eddy/wind interactions on biological new production and eddy kinetic energy. Journal of Geophysical Research 114, C05023, doi:10.1029/2008JC005129. 
Foltz, G.R., Carton, J.A., Chassignet, E.P., 2004. Tropical instability vortices in the Atlantic ocean. Journal of Geophysical Research 109. doi: 10.1029/2003JC001942.

Fyfe, J.C., 1999. Climate simulations of African Easterly Waves. Journal of Climate 12, 1747-1769.

Garzoli, S.L., 1987. Forced Oscillations on the Equatorial Atlantic Basin During the Seasonal Response of the Equatorial Atlantic Program (1983-1984). Journal of Geophysical Research 92(C5), 5089-5100.

Grodsky, S.A., Carton, J.A., 2001. Coupled land/atmosphere interactions in the West Africa Monsoon. Geophysical Research Letters 28(8), 1503-1506.

Grodsky, S.A., Carton, J.A., Provost, C., Servain, J., Lorenzzetti, J.A., McPhaden, M.J., 2005. Tropical instability waves at $0^{\circ} \mathrm{N}, 23^{\circ} \mathrm{W}$ in the Atlantic: A case study using Pilot Research Moored Array in the Tropical Atlantic (PIRATA) mooring data. Journal of Geophysical Research 110(C08010), doi: 10.1029/2005JC002941.

Guiavarc’h, C., Treguier, A.M., Vangriesheim, A., 2008. Remotely forced biweekly deep oscillations on the continental slope of the Gulf of Guinea. Journal of Geophysical Research 113(C06002), doi:10.1029/2007JC004471.

Guiavarc'h, C., Treguier, A.M., Vangriesheim, A., 2009. Deep currents in the Gulf of Guinea: along slope propagation of intraseasonal waves. Ocean Science, 5, 141-153.

Han, W., Webster, P.J., Lin, J., Liu, W.T., Fu, R., 2008. Dynamics of intraseasonal sea level and thermocline variability in the equatorial Atlantic during 2002-2003. Journal of Physical Oceanography 38, 945-967.

Hansen, D.V., Paul, C.A., 1984. Genesis and effects of long waves in the equatorial Pacific. Journal of Geophysical Research 89, 10431- 10440.

Hashizume, H., Xie, S.P., Liu, T.W., Takeuchi, K., 2001. Local and remote atmospheric response to tropical instability waves: a global view from space. Journal of Geophysical Research 106, 10173-10185.

Houghton, R.W., Colin, C., 1987. Wind-driven Meridional Eddy Heat Flux in the Gulf of Guinea. Journal of Geophysical Research 92(C10), 10777-10786.

Janicot, S., Sultan, B., 2001. Intra-seasonal modulation of convection in the West African monsoon. Geophysical Research Letters 28(3), 523-526.

Jochum, M., Malanotte-Rizzoli, P., Busalacchi, A.J., 2004. Tropical instability waves in the Atlantic Ocean. Ocean Modelling 7, 145-163.

Jochum, M., Murtugudde, R., Ferrari, R., Malanotte-Rizzoli, P., 2005. The impact of horizontal resolution on the tropical heat budget in an Atlantic Ocean Model. Journal of Climate 18, 841-851. 
Jochum, M., Cronin, M.F., Kessler, W.S., Shea, D., 2007. Observed horizontal temperature advection by tropical instability waves. Geophysical Research Letters 34, doi:10.1029/2007GL029416.

Kistler, R., Kalnay, E., Collins, W., Saha, S., White, G., Woollen, J., Chelliah, M., Ebisuzaki, W., Kanamitsu, M., Kousky, V., van den Dool, H., Jenne, R., Fiorino, M., 2001. The NCEP/NCAR 50-year reanalysis: Monthly Means CD-ROM and documentation. Bulletin of the American Meteorological Society 82(2), 247-268.

Kummerow, C., Barnes, W., Kozu, T., Shiue, J., Simpson, J., 1998. The Tropical Rainfall Measuring Mission (TRMM) Sensor Package. Journal of Atmospheric and Oceanic Technology 15, 809-817.

Large, W.G., Pond, S., 1981. Open ocean momentum flux measurements in moderate to strong winds. Journal of Physical Oceanography 11, 324-336.

Large, W., Yeager, S., 2004. Diurnal to decadal global forcing for ocean sea-ice models: the data sets and flux climatologies. NCAR Technical Note: NCAR/TN-460+STR. CGD Division of the National Center for Atmospheric Research.

Large, W.G., Yeager, S.G., 2008. The global climatology of an inter-annually varying air-sea flux data set. Climate Dynamics, in press.

Levitus, S., 1998. World Ocean Atlas (1998). http://www.ifremer.fr/sismer/references/climatologies.

Madec, G., 2008: NEMO ocean engine. Note du pole de modélisation, Institut Pierre-Simon Laplace, France, No 27, ISSN 1288-1619.

Menkès, C.E., Kennan, S.C., Flament, P., Dandonneau, Y., Masson, S., Biessy, B., Marchal, E., Eldin, G., Grelet, J., Montel, Y., Morlière, A., Lebourge-Dhaussy, A., Moulin, C., Champalbert, G., Herbland, A., 2002. A whirling ecosystem in the Equatorial Atlantic. Geophysical Research Letters 29, doi: 10.1029/2001GL014576.

Menkès, C.E., Vialard, J.G., Kennan, S.C., Boulanger, J.P., Madec, G.V., 2006. A modeling study of the impact of Tropical Instability Waves on the heat budget of the Eastern Equatorial Pacific. Journal of Physical Oceanography 36, 847-865.

Mounier, F., Janicot, S., Kiladis, G.N., 2007. The West African Monsoon Dynamics. Part III: The Guinean Quiasi-Biweekly Mode of Convection. Journal of Climate 20, 1487-1503.

Peter, A.C., Le Hénaff, M., du Penhoat, Y., Menkès, C.E., Marin, F., Vialard, J., Caniaux, G., Lazar, A., 2006. A model study of the seasonal mixed layer in the equatorial Atlantic. Journal of Geophysical Research 111 (C06014), doi:10.1029/2005JC003157.

Philander, S.G.H., 1976. Instabilities of zonal equatorial currents. Journal of Geophysical Research 81, 3725-3735.

Philander, S.G.H., 1978. Instabilities of zonal equatorial currents: II. Journal of Geophysical Research 83, 3679-3682. 
Pytharoulis, I., Thorncroft, C., 1998. The low-level structure of African Easterly Waves in 1995. Monthly Weather Review 127. 2266-2280.

Qiao, L., Weisberg, R.H., 1995. Tropical instability wave kinematics: Observations from the Tropical Instability Wave Experiment (TIWE). Journal of Geophysical Research 100, 8677-8693.

Qiao, L., Weisberg, R.H., 1998. Tropical instability wave energetics: The Tropical Instability Wave Experiment. Journal of Physical Oceanography 28, 345-360.

Richardson, P.L., McKee, T.K., 1984. Average Seasonal Variation of the Atlantic Equatorial Currents from Historical Ship Drifts. Journal of Physical Oceanography 14, 1226-1238.

Seo, H., Jochum, M., Murtugudde, R., Miller, A.J., 2006. Effect of ocean mesoscale variability on the mean state of tropical Atlantic climate. Geophysical Research Letters 33, doi:10.1029/2005GL025651.

Seo, H., Jochum, M., Murtugudde, R., Miller, A.J., Roads J.O., 2007. Feedback of Tropical Instability-Wave-Induced Atmospheric Variability onto the Ocean. Journal of Climate, 20, 5842-5855.

Servain, J., Busalacchi, A.J., McPhaden, M.J., Moura, A.D., Reverdin, G., Vianna, M., Zebiak, S.E., 1998. A Pilot Research Moored Array in the Tropical Atlantic (PIRATA). Bulletin of the American Meteorological Society 79, 2019-2031.

Smith, S.R., Legler, D.M., Verzone, K.V., 2001. Quantifying uncertainties in NCEP reanalyses using high quality research vessel observations. Journal of Climate 14, 40624072.

Smith, W.H.F., Sandwell, D.T., 1997. Global seafloor topography from satellite altimetry and ship depth sounding. Science 277, 1957-1962.

Le Sommer, J., Penduff, T., Theetten, S., Madec, G., Barnier, B., 2009. How momentum advection schemes influence current-topography interactions at eddy-permitting resolution. Ocean Modelling 29, 1-14.

Wainer, I., Clauzet, G., Servain, J., Soares, J., 2003. Time scales of upper ocean temperature variability inferred from the PIRATA data (1997-2000). Geophysical Research Letters 30(5), doi: 10.1029/2002GL015147.

Weingartner, T.J., Weisberg, R.H., 1991. On the annual cycle of equatorial upwelling in the central Atlantic Ocean. Journal of Physical Oceanography 21, 68-82.

Weisberg, R.H., Weingartner, T.J., 1988. Instability Waves in the equatorial Atlantic Ocean. Journal of Physical Oceanography 18, 1641-1656.

Weisberg, R. H., 1985. Equatorial Atlantic velocity and temperature observations: FebruaryNovember 1981. Journal of Physical Oceanography 15, 533-543. 
Yanai, M., Murakami, M., 1970. Spectrum analysis of symmetric and anti-symmetric equatorial waves. Journal of Meteorological Society of Japan 48, 331-346. 


\section{List of figures}

Figure 1. Sea Surface Temperature (SST) in 2001 as observed from TMI observations and simulated in LYSIM, QSCAT and ERA40 (from top to bottom). Left: longitude-time diagram along $1.5^{\circ} \mathrm{N}$ from May to October 2001. Black dashed lines refer to the propagation of cold events as observed in TMI data (at an estimated phase speed of $42 \mathrm{~cm} / \mathrm{s}$ ). Right: snapshot of horizontal distribution on 29 July 2001 . Unit is ${ }^{\circ} \mathrm{C}$ and interval between contours is $0.5^{\circ} \mathrm{C}$. Thick continuous lines in the longitude-time diagram indicate 29 July 2001.

Figure 2. Time-Latitude diagrams of SST at $20^{\circ} \mathrm{W}$ as observed from TMI observations and simulated in LYSIM, QSCAT and ERA40 (from top to bottom), from May to September of each year between 2000 and 2004 (from left to right). Unit is ${ }^{\circ} \mathrm{C}$ and interval between contours is $0.5^{\circ} \mathrm{C}$. A 3-day running average has been applied in time to remove the day-to-day noise in TMI SST data.

Figure 3. Time-latitude diagrams of meridional velocity at $20^{\circ} \mathrm{W}$ as simulated in LYSIM, QSCAT and ERA40 (from top to bottom), from April to September of each year between 2000 and 2004 (from left to right). Unit is $\mathrm{cm}^{-\mathrm{s}^{-1}}$ and contour interval is $10 \mathrm{~cm} . \mathrm{s}^{-1}$. A 7-day running average has been applied in time to filter out sub-weekly variability.

Figure 4. Time series of EKE in $\mathrm{cm}^{2} / \mathrm{s}^{2}$ between 2 and 50 days for QSCAT (red line), LYSIM (blue line) and ERA40 (black line) simulations, at five locations: (a) $28^{\circ} \mathrm{W}, 0^{\circ} \mathrm{N}$ at $10 \mathrm{~m}$ depth, (b) $28^{\circ} \mathrm{W}, 0^{\circ} \mathrm{N}$ at $100 \mathrm{~m}$ depth, (c) $28^{\circ} \mathrm{W}, 3^{\circ} \mathrm{N}$ at $10 \mathrm{~m}$ depth, (d) $15^{\circ} \mathrm{W}, 0^{\circ} \mathrm{N}$ at $10 \mathrm{~m}$ depth, (e) $4^{\circ} \mathrm{W}, 0^{\circ} \mathrm{N}$ at $10 \mathrm{~m}$ depth. Note the difference scale in the energy axis in (b).

Figure 5. Mean zonal currents in boreal summer (June to August) for the period 2000-2001: horizontal distribution at the surface (top) and meridional section along $23^{\circ} \mathrm{W}$ (bottom), for QSCAT (left), LYSIM minus QSCAT (middle) and ERA40 minus QSCAT (right). Positive (resp. negative) values are in grey (resp. white) and continuous (resp. dashed) lines. Thick lines refer to the 0 isotach. Contour interval is $10 \mathrm{~cm} / \mathrm{s}$.

Figure 6. Time-latitude diagrams of SST (2 upper lines) and meridional velocity (2 lower lines) as simulated in M-LYSIM (lines 1 and 3) and in M-QSCAT (lines 2 and 4), from May to September of each year between 2000 and 2004 (from left to right). Interval between contours is $0.5^{\circ} \mathrm{C}$ for SST and $10 \mathrm{~cm} . \mathrm{s}^{-1}$ for velocities. Thick lines in velocity diagrams refer to the 0 isotach.

Figure 7. Variance spectra of both wind components for PIRATA mooring data and for QuikSCAT, LYDS and ERA-40 at $0^{\circ} \mathrm{N}, 23^{\circ} \mathrm{W}$, for the period 2000-2001 (upper) and 20002003 (lower). Unit is $\left(\mathrm{N} / \mathrm{m}^{2}\right)^{2} /(\mathrm{cpd})$. The spectra have been smoothed with a running-average to increase the degrees of freedom (linearly increasing from 8 to 80 over the frequency range). The vertical spacing between the bold lines corresponds to 95\% confidence interval.

Figure 8. Horizontal distribution of wind stress variance in the frequency ranges 2-10 days (top), 10-20 days (middle) and 20-50 days (bottom) for LYDS (left), QuikSCAT (middle) and ERA-40 (right). Contour interval is $0.2510^{-4}\left(\mathrm{~N} / \mathrm{m}^{2}\right)^{2}$. The computation has been performed over the period 2000-2001. A running median filter over $2^{\circ}$ in longitude has been applied to filter out small-scale noise in QuikSCAT winds. Note that color bars have different scales. 
Figure 9. Horizontal distribution of mean eddy kinetic energy (EKE) for the frequency ranges 2-10 days (top), 10-20 days (middle) and 20-50 days (bottom) in LYSIM (left), QSCAT (middle) and ERA40 (right) simulations. Contour interval is $10 \mathrm{~cm}^{2} / \mathrm{s}^{2}$. The computation has been performed over the period 2000-2001. Note that color bars have different scales.

Figure 10. Time-depth distribution of meridional velocity from May to October 2000 at $23^{\circ} \mathrm{W}, 3.5^{\circ} \mathrm{N}$ for LYSIM, QSCAT, ERA40, and M-LYSIM (from top to bottom). Positive (resp. negative) values are in grey (resp. white). Contour interval is $10 \mathrm{~cm} / \mathrm{s}$. The mixed layer depth (thick black line) and the $20^{\circ} \mathrm{C}$ isotherm depth (dashed black line) are superimposed.

Figure 11. Time evolution of the mean EKE averaged over $30^{\circ} \mathrm{W}-15^{\circ} \mathrm{W}$ and $6^{\circ} \mathrm{S}-6^{\circ} \mathrm{N}$. (a) EKE for periods lower than 50 days for LYSIM (thick line) and M-LYSIM (gray line), and for periods between 20 and 50 days (dotted line) and between 2 and 20 days (thin line) for LYSIM. (b) Same as (a) but for QSCAT and M-QSCAT simulations. Units are $\mathrm{cm}^{2} / \mathrm{s}^{2}$. 


\begin{tabular}{|c|c|c|}
\hline simulation & wind fields & temporal resolution \\
\hline LYSIM & LYDS & 6-hourly wind velocity \\
M-LYSIM & LYDS & Monthly wind stress \\
QSCAT & QuikSCAT & daily wind velocity \\
M-QSCAT & QuikSCAT & Monthly wind stress \\
ERA40 & ERA-40 & 6-hourly wind velocity \\
\hline
\end{tabular}

Table 1. Acronyms of the different NATL4 simulations used in this study. The simulations differ by the wind fields used as forcing and their temporal resolution. 